\title{
The Formation Process of Chu Teh-chun's Abstract Painting Style
}

\author{
Feng Liu \\ School of Fine Arts \\ Jiangsu Normal University \\ Xuzhou, China 221116
}

\begin{abstract}
This paper studies the formation process of Chu Teh-chun's abstract painting style, summarizes it into three stages: transformation period from figurative painting to abstract painting, development period returning to traditional culture and mature period of his style, and analyzes the key factors influencing the development of each stage to summarize the artist's pursuit of the spirit of the times, the return to cultural traditions and the exploration of the essence of art in the formation process of style.
\end{abstract}

Keywords—Chu Teh-chun; abstract painting; style

\section{INTRODUCTION}

Painting style refers to a unique beauty conveyed by paintings as a whole. It is a relatively stable aesthetic tendency, technical features and expressions in the works as well as an external imprint reflecting the artist's personal ideas, aesthetic ideals, and spiritual temperament, etc. The essence is the artist's own spiritual temperament and independent personality. Mr. Chu Teh-chun is a worldrenowned master of abstract painting and the first Chinese race academician of Fine Arts institute of the French Academy. His abstract paintings are of great momentum with the rhythm of light and shadowy, perfectly combining the delicateness of oriental ink painting with the beauty of Western oil paintings. He combines the spirit of Chinese traditional painting with the form of Western abstract painting to form a unique abstract painting style with distinct Chinese artistic conception.

Mr. Chu Teh-chun graduated from Hangzhou Art College in his early years and went to France to pursue artistic ideals in 1955. Before going to France, he had been concentrating on the study of realistic oil paintings. His first real portrait in France also won the Sharon Award. But then he resolutely turned to abstract painting. After years of exploration, he finally formed his own unique abstract painting style. How did he achieve this huge transformation? This paper has studied and summarized this.

\section{The PuRsuit OF THE SPIRIT OF THE TIMES - TRANSFORMATION PERIOD FROM FIGURATIVE PAINTING TO ABSTRACT PAINTING (ABOUT THE EARLY 1956-60s)}

\section{A. The Influence of De Stael}

In May 1956, Chu Teh-chun saw a retrospective of the Russian painter Nikola de Stael for the first anniversary of his death at the Museum of Modern Art in Paris. The exhibition gave him a great shock and impact. Stael's painting attitude touched him very much. His free-spirited painting attitude shocked him. He greatly appreciated the keen sense of his works, the free-spirited picture effect and the transparency of paints in the picture. He understands that the most valuable thing in painting is the ability to express his will freely. The beauty of abstract painting with just right freedom and connotation is the ultimate realm that modern art should pursue. After visiting this exhibition, he decided to completely abandon figurative painting, get rid of the shackles of the image of object, and pursue free abstract art. Stael began to draw abstract paintings since 1941. He once held an abstract painting exhibition with Kandinsky, but soon he began to change his mind and care about the problem between nature and abstraction. He believed that the abstract painting does not necessarily negate the natural image. The style of painting changed from pure abstraction to a new style that integrate concretization and abstraction and preserved the abstract form while indicating the theme. Western critics called him the second generation abstract master. It is no accident that Stael has a decisive influence on $\mathrm{Chu}$ Teh-chun, because his half-figurative and half-abstract and natural-looking style is similar to China's "image" painting, which is also the aesthetic basis of Chu Teh-chun.

Chu Teh-chun began to explore the first batch of invisible paintings with the inspiration of streetscape in Paris. From these early works, such as "Street View" in 1955, "City Lookout" in 1956, and "nightfall in the City", etc., we can clearly see the influence of Stael. Stael's bold, rich, yet fresh and natural style has had a great impact on him. Stael abstracts the objects in reality and turns them into flat patches in the picture. The size, brightness, and color of these blocks have an intrinsic relationship. Chu Teh-chun also made an abstract transformation in the transformation of the relationship between object and form, space and plane, which not only constructs the formal relationship in the 
picture, but also tries to express emotions in the simplified structure. In the same year, his abstract oil paintings were invited to participate in the "Today's Paintings" exhibition in Paris. His name was ranked in the 30th of the 112 painters in French. He was excited to discover that his works is displayed with the works of masters he admired, such as Picasso and Framanck, for the first time.

\section{B. The Influence of Art Informel}

With more contact with the Paris School abstract painter group, in the late 1950s, Chu Teh-chun's works have undergone new changes. He began to give priority to the stable spatial relationship, and the thick black structural line occupied the center of the picture. $\mathrm{Zu}$ Wei called it the "iron wire period" vividly, which means the characteristics of exposing the iron wire. The Paris Abstract School is an important member of the European art informel movement, and they are directly or indirectly influenced by the rigorous structural shape of the geometric abstractionist Mondrian. Mondrian once advocated to "abandoning the contingency of painting and all elements that are limited by symbols or emotions, and create a new aesthetic of purely geometric abstract paintings based on the pure relationship between lines and colors."[1] Hatton and Soulage often use black structural lines in pictures, but they emphasize an irrational semi-automatic technique and lyrical abstraction of the brushwork. The black structure lines are also rich and varied, with their own expressions. . The concept and time of European art informel are roughly the same as that of American abstract expressionism, and they have a common artistic orientation and close ideological origin, so it is also known as European abstract expressionism. However, the abstract expressionism of the United States has cooled down quickly after a period of enthusiasm. The art informel has shown its long-lasting vitality in Europe and the world. The source of this vitality is European splendid tradition of plastic arts and deep-rooted scientific rational spirit.

In the movement of the Paris School, Chu Teh-chun was inevitably influenced by the painters subtly. At this stage, he created a large number of works with black-line structure, and made a lot of explorations on the practice of the picture structure, such as the 1960 works "Red rain Village and white cloud house", "A little red in the green cluster", and "Red-colored flowers" and so on. The center structure of these works is a solid thick black line. The background has a dominant color, and various small color blocks of different areas play the role of activating picture and widening the picture rhythm. From the clear structure and stable relationship in the picture, we can see the influence of the European art informel movement on his creative concept, and it is also the stage in which he deeply understands the principles of abstract art form. However, due to the experiment and exploration process, $\mathrm{Chu}$ Teh-chun was not very satisfied with the works in this period later. He said: "Although it is powerful and strong, I am not satisfied with the line outside the color block, and it is simplistic."[2]

\section{THE RETURN OF CULTURAL TRADitions - THE DeVelopment Period of AbStRact Style (ABout 1960S-} 1970s)

\section{A. The Influence of Calligraphy Practice}

In 1959, Chu Teh-chun began to study the long-lost calligraphy. In his calligraphy study, he not only expressed his passion for writing and homesickness, but more importantly, he discovered the inspiration source for abstract creation in the calligraphy. In the process of studying the relationship between the two, Chu Teh-chun discovered that many ancient Chinese calligraphy concepts are close to the principles of modern abstract art. The ancients said: "Most of painters are good at calligraphy". The calligraphic style, vigour of strokes in calligraphy, technique of calligraphy, and brush stroke, etc. imply the spirit and style of Chinese culture, which can be used as reference in painting. The wild cursive he loves is a typical abstract art. It uses free style and sharp lines, and brings the freehand brushwork to the extreme. The beauty of the lines in the ups and downs and the change is an abstract beauty.

After a period of calligraphy study, Chu Teh-chun began to conceive how to transplant the expressive force of calligraphy into abstract paintings. He began to try to introduce calligraphy elements into oil painting creation. In the work "Poetics of the Arctic" in 1961 and "Composition" in 1962, it can be found that the thick lines of the original structure in the painting begin to loosen and blur, and the black frame at the center of the picture spreads around. The loose lines entangled together again to form a group and collide all around, as if it contains some kind of power to break away from the background. The brushstrokes also turned into a dynamic hurry, sweeping through the picture like a gust of wind and left a trace of movement. From the madness and excitement like wild cursive, we feel the passion of the painter. The practice of calligraphy innovation on the picture brings his creation to a higher level.

In 1960, Chu Teh-chun was invited to participate in the "Paris School" exhibition with oil paintings with Chinese calligraphy images and was promoted to be one of the members of the new generation of Paris School. The strong calligraphic lines and color block structure in his works are calm and have a sense of rhythm, which has attracted the attention of Western art critics. French poet and art critic Hubert Juin was the first loyal appreciator and critic of Chu Teh-chun. As the authority of French literary and art critics in the 20th century, he praised Chu Teh-chun's style change: "This Chinese painter seems to re-identify the unique writing advantages of Chinese traditional calligraphy after contacting with the Paris School. We know that he has painted works that have been deeply influenced by the Fauvism, but in just a few years, he has found his own way of writing. These series of works give us a strong and vivid image. "[2] Pierre Cabanna analyzed: "His painting hopes more freedom. At the same time, the abstract painters of the Paris School draw on the so-called 'expression painting' from the Far East art, let the hands follow the emotion to spontaneously move, and gather the world of perception and passion with the bold and quick strokes. The symbols, touch and calligraphy-like 
handling of brush are popular in France in the 1960s. He just inherited it, but he took a step ahead of others. "[3] Calligraphy, as the core of Chinese art, has become an important symbol of Chu Teh-chun's cultural identity as a Chinese abstract artist.

\section{B. The Impact of Ink Painting Practice}

In addition to calligraphy, he also began to paint ink paintings in the evening. The study of ink painting played a more important role in the change of his oil painting style. Chu Teh-chun said: "In 1961, I began to miss the interest of ink painting, but at that time, I could not buy rice paper in Paris. I only used blotting paper to paint and comforted my homesickness. I painted thinner, which is related to my past painting of ink painting in China. This is a point I have inherited from the foundation of Chinese painting. "[2] Chu Teh-chun has been influenced by traditional art since childhood. With the basis from the teacher Pan Tianshou, he thinks when working hard, combines his feelings with new ink painting, and integrates them into the practice of abstract oil painting. Affected by ink painting, the technique of thick scraping pigment by palette knife that Chu Teh-chun always used in abstract works disappeared, so the thick and rough picture was replaced by the warm and dynamic texture effect of ink. From many works of this period, such as "Source" in 1965, "No. 268 Composition", and "Late Autumn" in 1968, it can be seen that he turned the moist sensitivity of ink on the rice paper into the color of the canvas. The fusion of two different materials and artistic thinking formed his unique gentle and soft abstract oil painting texture. The artistic conception of the picture also began to move towards softness and vividness, and the dreamlike connotation of the oriental culture gradually is presented in his paintings. The various functions of "water" in the ink painting are transplanted into the "oil" in the oil painting. With the lubrication of the oil, his handling of brush is smoother, and the calligraphy nature is further reflected. The original thick and hard structure gradually becomes a soft and gentle curve.

1970s was an important watershed for Chu Teh-chun. He returned to Chinese culture through ink painting and returned to the natural view of "unity of heaven and man". As a unique material of Chinese painting, rice paper has special properties and is very sensitive to the halo of water. It requires the painters' superb control ability, and the instantaneous change can produce an unexpected "image" effect. It is this particularity of the material of ink painting that enables Chinese traditional painters to perfectly unite themselves with materials, images and structures in the process of painting. Ink painting contains a rich Chinese aesthetic spirit. The important cosmology of "qi" and "virtual" aesthetic concepts in Chinese philosophy are contained in it. The important techniques of the randomness and imagery function are realized through halo of ink painting. Nature is no longer just an "object" to be constructed, but a "mental imagery" that becomes the spirit home of the artist. Critic Gao Tianmin pointed out that nature in Western art has always existed only as an object that artists observe and analyze. This relationship has created a paradox and strained relations: when artists try to approach nature, nature is further. Every time you approach and reenter the new close space. This kind of confusion and strained relations is always unsolvable by Western scientific rationality. Therefore, in the modern times, Western philosophers such as Heidegger and Deleuze tried to seek inspiration from Eastern philosophy, and thus saw a new world, which was closely related to traditional Chinese thought. In the eyes of the Chinese, man and nature are neither objectified nor separated, but an affirmation of the "outside world." This kind of affirmation is not the analysis and divestiture of objectification, but internalization and integration, a kind of integration of "heart" and "environment". [4]

The author believes that "inking" is a crucial change in the transition period of $\mathrm{Chu}$ Teh-chun's abstract painting. The attribute of "water" is realized in the abstract painting in the form of "oil", forming a unique formal language feature that truly belongs to him. A key breakthrough from the Western abstraction to the oriental imagery is completed. After thousands of years of precipitation, Chinese culture has formed a unique value and aesthetic orientation. It is extensive and profound, generous and harmony. It is the only ancient civilization that has not been interrupted. It was through ink painting that he returned to the Chinese tradition and completed the internal transformation process from the Western view of nature to the Eastern view of nature. Cabanne commented: "The time of nearly half a century spent on exploration, travel, deep exploration in art, and calligraphy practice since leaving China brought him closer to his roots."[3] "Chu Teh-chun's paintings have deep tradition, but this tradition is the meaning of his life rather than a burden. He is nurtured by a culture and a civilization. He does not deny this culture and civilization. They are the spiritual food of his thoughts, rhythms and color distribution. They are the direction for his actions and movements. ... Chu Teh-chun and his inner kingdom - China - live together, just like living with a living being. This is the China of painters, gods, the illusionist and the poet, the China belongs to him and the China that is inseparable with him for the lifetime. "[5] For this return and transformation, Chu Teh-chun said: "When I came to Europe and saw their abstract paintings, I immediately felt very close to Chinese literati paintings. After the romanticism appeared in Europe, it slowly approached the Chinese painting thoughts. In fact, the way that the East and the West take is the same. The painter must experience and understand the Eastern and Western cultures in a sincere manner to naturally mix them together... The culture and education of Chinese and foreigners are different and the background is different, so the paintings are naturally not the same. The Chinese who grow up with the influence of China's education and culture has indelible cultural thoughts be installed in the blood, which will directly affect his creative thinking. By the time the painting reaches maturity period, the breath of Chinese culture will naturally emerge. "[6] 
IV. THE EXPLORATION OF THE ESSENCE OF ART - THE MATURITY PERIOD OF ABStRACT STYLE (AFTER THE 1970S OR SO)

\section{A. The Influence of Rembrandt}

In 1970, Chu Teh-chun went to Amsterdam, the Netherlands, to visit Rembrandt's 300th birthday commemorative exhibition. He was very impressed with this exhibition and his painting attitude was changed a lot. During the visit, he stayed there from the opening of museum to closing. He felt that the quality and painting quality of Rembrandt's paintings were rare for generations. Rembrandt's unique technology of using light shows his superb classical imagery ability, and his work was also added with his own experience and observation. Because of this kind of empathy, Rembrandt is called "the prophet of civilization." Another showroom next to the Rembrandt exhibition, is exhibiting the works of European modernist painters. Chu Teh-chun went in and looked at it, but was surprised to find that there was no one inside. The exhibition of Rembrandt's paintings three hundred years ago was crowded, but why didn't people want to appreciate modern art? He repeatedly thought about this and concluded that many modern paintings stay on the surface, with poor content, rough picture, and low quality. This gave him a lot of shock and warning. Chu Teh-chun himself thought this was an important revelation of his second visiting paintings after he came to France. He realized that the most important significance of the artist's existence is the profound connotation of the work and the high level of picture quality. To do this, the painter must first have a sincere attitude, and be honest and sensible to be able to resonate with the viewer. No matter how the slogan of painting school changes, the work that does not have this condition will soon die out over time and be eliminated and forgotten by the times. [7]

From then on, his attitude towards painting was more strict and serious. He paid more attention to the quality of the picture effect, and began to explore the profound aspects of creation. The author believes that this "deepness" is beyond the surface and form of painting, and goes deep into the deep essence of artistic creation. It is also this inspiration that makes Chu Teh-chun's abstract art step into the inner spiritual exploration from the external form exploration in the transition period, thus truly entering the real mature stage of artistic creation. Critic Shui Tianzhong believes that Rembrandt has triggered Zhu Dequn's thinking on the realm of painting art and the inner humanistic spirit. Comparing his paintings in the 1950s and 1960s with those in the 1970s, the differences between them can be clearly found. Although the early works also showed a kind of momentum and vitality, the works after the 1970s contained a richer spirit. This is the artist's view and deep thinking on the origin of life in the artistic journey, which resulted from the role of various factors such as the accumulation of his life experience and mental maturity. Rembrandt's influence on Chu Teh-chun's artistic spirit and vitality level raised the lyricism of Chu Teh-chun's paintings to a broad spiritual connotation. Without these, Chu Teh-chun's abstract paintings may be limited to the superficial chic, but it is difficult to enter the mysterious realm of life. [8]
At the same time, Chu Teh-chun also absorbed Rembrandt's control of "light", and his use of light is more free and subjective. He also formed multiple light sources according to the needs of the picture, so it is more varied and moving. Inspired by the dramatic use of light in Rembrandt's works, Chu Teh-chun's works began to widen the light and shade relations of the picture with light and also created his own multidimensional space. At the same time, he converted the concept of yin and yang in Chinese traditional philosophy into the light source and shadow in the oil painting, and presented the multidimensional space on his own picture, such as the burial of life in 1976 and the Jiguang landscape in 1978. French art critic Morris Barnier analyzed: "Chu Teh-chun's space is not a classical perspective. It can be said to be a multidimensional space. The ingenious selection of colors and the layout of the small squares in the paintings make the tone have a subtle change under the color penetration. Painting is space as well as the structure. " [2]

\section{B. The Influence of Chinese Traditional Poetry}

In the late 1970s, Chu Teh-chun increased the reading and understanding of traditional Chinese poetry. Through the integration of feelings and images in poetry, he once again gained the jump and sublimation of the perception system. He said: "I like reading Chinese poetry most, especially the Full Collection of Tang Poems and the Whole Poetry of Song Dynasty. Chinese poetry and painting are inseparable. Chinese poetry is subtle and abstract, with cultural implication, and the artistic conception it creates is the artistic conception that I want to convey in my paintings. In fact, the realm of Chinese painting is the realm of Chinese poetry. Poetry and painting cannot be separated, including calligraphy. The starting point of Chinese literati painting is poetry. A few years later, I realized that painting Chinese things must draw on the form of Western painting and express the spirit of Chinese painting. "[2] He believes that the true connotation of the artist should be the cultivation of literature and art and the mixture of painting spirit and nature, instead of the skill of painting. The skill is the stiff thing. The paintings of Ming and Qing Dynasties are bad because of copying the predecessors, so there is only one empty shell left after copying. He pointed out that ancient Chinese painters pay attention to cultural accomplishment and enriches their paintings with poetry. Since the Tang and Song Dynasties, Wang Wei has ha the saying that "there are paintings in poetry and there is poetry in paintings." When the painting academies in Song Dynasty select painters, they often used poems as examination questions, such as "there is fragrance on the horseshoe after stepping on flowers", to test the painter's ability to transform poetry to painting. He believes that one of the most important skills of abstract painting is the artist's fantasies, and poetry can cultivate the artist's ability to fantasy, so that they can use the basic skills of painting to express it. Only through the cultivation of knowledge and literature will the content of painting not be empty.

Inspired by the artistic conception of poetry, Chu Tehchun's paintings, after experiencing most of the black, white 
and grey pictures in the 1960s and 1970s, finally appeared in saturated colors in the mid-1980s. For example, in 1987's "Cold", 1995's "Basic Elements", and 2002's "Amplitude", the collision and balance between colors produced an unusual gorgeous visual effect and became the protagonist of the picture. The dreamlike concept of poetry gives the audience unlimited imaginary space. Critic Xiao Xiaolan believes that his works after this period are no longer obsessed with the characteristics of Chinese ink interest that is different from the Western abstraction in the transition period. The composition became more arrogant and wilder, and the color is more violent and fierce. The brush strokes are completely unscrupulous, and the picture implication presents the highest level of great momentum and free expression. These all give people a stronger and deeper sense of beauty and thinking. This is a transcendent master image. The artistic goal that Chu Teh-chun struggled for a lifetime is finally achieved. Xiao Xiaolan believes that Chu Teh-chun enter the "without rule" stage when his individual spirit can play freely after he has learned and transcended the "rules" of abstract existing norms and patterns. The scope of his artistic examination has become broader, and the words of painting expression are more abundant and personal. This is another "breakthrough" of Chu Teh-chun's artistic creation. He has leaped from the previous cultural experience, whether it is the influence of Western abstract art or the oriental traditional culture, released extremely powerful life energy and reached the highest level of artistic creation: the complete free release of life consciousness. The Chinesestyle rhythm flow and romantic spirit are still there, but it has transcended the external sense of form and has become a surging soul hidden inside the picture. [9]

Chu Teh-chun completed his entire exploration of free abstract art. He said: "In the past, although I knew that painting was to paint my own feelings, but it is difficult to draw the feelings. I just tried very hard to use oil paint and lines to pursue my feelings and strive to paint. Although sometimes I can draw something by chance, I can express this feeling after slow experiencing for half a year, or even one year. I have been painting for 20 years. Today, I can finally put all the interests in my heart almost completely, and now I feel free to express what I want to express in my heart." For such a change, Chu Teh-chun said: "I don't specifically paint in accordance with Chinese or Western traditions. These two are united in my heart."... For a painter who is completely involved in painting, he does not think about what kind of painting he is painting. Whether it is Chinese painting is not important." "[10] He believes that a highly developed civilization should be the wealth shared by all mankind. Both the East and the West paintings, as long as they are beneficial to the progress of human civilization, should be recognized. Indeed, when art rises to the highest level, it should transcend national boundaries to become the common spiritual wealth of all mankind.

\section{CONCLUSION}

The style of painting objectively exists. It is an important part of the aesthetics of painting, which is formed by longterm artistic accumulation. It is also a relatively stable artistic language. A painter forming a personal style marks the maturity of his painting art. Creating new programs, new styles, and new faces is the goal that every painter strives for even for a lifetime.

Through the above analysis of the formation process of Chu Teh-chun's abstract painting style, it can be seen that his efforts in the process of blending Chinese and Western paintings and searching for his own artistic style have given us many inspirations. In the great changes of the times and cultures, Chu Teh-chun was brave in exploring and adventurous. In order to pursue the spirit of the times, he went to France to follow the art in heart. After experiencing the influence of modernist art, he absorbed the quintessence of Western modern abstract art and took a solid step for the development of Chinese modern art; at the same time, he did not stop the simple imitation of Western abstraction, but through his profound Chinese culture, he deeply integrated Chinese and Western art spirits, so that the traditional Chinese calligraphy art, ink spirit, the tradition of landscape painting and the aesthetics of classical poetry are all injected into the external form of Western modern abstract paintings. As a sensitive and profound artist, he has the sincere feeling to art and the unremitting pursuit of the essence of art. Through deep comprehension of the essence of art creation in East and West, he eventually formed his own unique abstract artistic style of light and lyricism. With his lifelong artistic practice and pursuit, he pointed out a direction for the future development of Chinese contemporary art on how to deal with the traditional artistic spirit and the modern demands of the times.

\section{REFERENCES}

[1] Chen Zhixiong. Abstract Art Theory [M]. Beijing Tsinghua University Press, 2005:30.

[2] Zu Wei. Chu Teh-chun's biography [M]. Shanghai: Wenhui Publishing House, 2001: 56, 138, 188, 171, 171 .

[3] [French] Pierre Cabanna. Chu Teh-chun [M]. Beijing: Sanlian Bookstore, 2000: 21, 35.

[4] Gao Tianmin. China's Wisdom Western Eyes [M]//Chu Teh-chun. Shanghai: Shanghai Paint Shop Press, 2005: 25.

[5] [French] Pierre Cabanne. Chu Teh-chun's Exhibition [M]. Japan: Ueno Art Museum, 2007: 56.

[6] Yu Xi. Chu Teh-chun - grand Life [J]. China \& the World Cultural Exchange: 2003.04.30.

[7] [French] Chu Teh-chun. My painting process [J]. Literature \& Art Studies: 2000, 9: 102-106.

[8] Shui Tianzhong. Chu Teh-chun and his paintings [J]. Literature \& Art Studies: 2000.05.113.

[9] Xiao Xiaolan. Chu Teh-chun's Free Spirit [M]//Chu Teh-chun. Shanghai: Shanghai Paint Shop Press, 2005:39.

[10] Xing Xiaozhou. Interview with Xing Xiaozhou [M]//Chu Teh-chun's Painting Exhibition. Guangzhou: Guangdong Museum of Art, 2000:26. 